\title{
Effect of prenatal exposure to bisphenol a on the vagina of albino rats: immunohistochemical and ultrastructural study
}

\author{
R.A.M. Ahmed ${ }^{1}$, T.A. ElGhamrawy², E.E.A. Salama ${ }^{3}$ \\ ${ }^{1}$ Department of Histology and Anatomy, Faculty of Medicine, Cairo and King Saud University, Saudi Arabia \\ 2Department of Anatomy, Faculty of Medicine, Cairo University, Egypt \\ ${ }^{3}$ Department of Anatomy, Faculty of Medicine, Al Azhar and King Saud University, Saudi Arabia
}

[Received 5 May 2014; Accepted 24 May 2014]

Background: Bisphenol-A (BPA) is an industrial chemical, used to manufacture polycarbonate and numerous plastic articles. It has been found to cause biological effects, mimic that of oestrogen. It belongs to a group of chemicals termed "endocrine disruptors" able to disrupt the chemical messenger system in the body. Aim of the study was to demonstrate the biological effects of BPA on the vagina of female rats, with the prediction of the neoplastic changes in relation to its potential impact.

Materials and methods: Sprague-Dawley gravid dams were divided into three groups (10 per group): G1 - control group had an equivalent volume of sesame oil to that taken in the treated groups, G2 - group was administered by gavage $0.1 \mathrm{mg} \mathrm{BPA} / \mathrm{kg}$ body weight (low-dose group) per day, and G3 - group was administered $50 \mathrm{mg}$ BPA/kg body weight (high-dose group) per day, dissolved in sesame oil. Treatment was carried out on gestation days 10 through 20. The female offsprings of each group were weaned at day 21 and the vagina was dissected when became 3 months old for histological, immunohistochemical analysis (for detection of oestrogen receptors $\alpha$ [ER $\alpha$ ], and the proliferation marker Ki-67), and ultrastructural study.

Results: The low dose group showed degeneration of the epithelial lining with focal patches of decreased epithelial layers. The high dose group revealed cytoplasmic hydropic degeneration, and the pyknotic nuclei of epithelial cells. Oestrogen receptors demonstrated a significant decrease of positive cells in low dose treated group and this decrease markedly accentuated in the high dose one. Positive nuclei for Ki-67 were markedly increased with increasing doses of BPA. Electron microscopic study revealed cytoplasmic degeneration, vacuolation and mitochondrial degeneration in both treated groups.

Conclusions: BPA showed an obvious mix of degenerative and proliferative histological changes and clear damage of the cellular organelles. This stressful condition may predispose to neoplastic changes of the vagina. (Folia Morphol 2014; 73, 4: 399-408)

Key words: bisphenol A, rat vagina, prenatal exposure, oestrogen receptors, Ki-67, ultrastructure, endocrine disrupter

Address for correspondence: Dr R.A.M. Ahmed, Associate Professor of Histology, Department of Histology and Anatomy, Faculty of Medicine, Cairo and King Saud University, tel: +966509019047, e-mail: drraeesama@gmail.com 


\section{INTRODUCTION}

Bisphenol A (BPA, 4,4'-isopropylidenediphenol) is widely used to manufacture numerous plastic products including food can linings and clear plastic bottles and several population studies have reported a high degree of human exposure [4, 42]. There is controversial data about the safety of these products. Extensive safety research on BPA has shown that consumer products made with BPA are safe for their intended uses and pose no known risks to human health [10]. On the contrary, a large number of in vivo studies have reported adverse effects concerning low-dose exposures to BPA, even below the current reference dose [41]. Phenol-containing molecules, such as BPA, have been reported to exert weak oestrogenic activities. Its activity on the different tissues may involve oestrogen receptors (ERs) and ER-mediated pathways in vivo and in vitro, so it is considered as an oestrogenic chemical and endocrine disruptor (ED) [6].

Studies in experimental animals have shown that very low doses of endocrine-disrupting chemicals, in particular BPA, in the range of human exposures can exert effects if administered during development [20]. An increasing number of "low-dose" studies have suggested that perinatal BPA exposure is associated with a variety of abnormalities in the female reproductive tissues, including-early onset of vaginal opening [12], and altered vaginal and uterine histology [30, 31]. Low-dose exposure is particularly important because of its relevance to the levels experienced by the general human population [4, 37].

Experimental animal models have shown an oestrogenic effect of BPA, and thus an endocrine disrupting action that may have long-term effects on the endocrine system, influencing tumour development later in life [41]. In addition to its hormonal effect, prenatal exposure to BPA has been associated with morphological and functional alterations of the male and female genital tracts and mammary glands that may predispose the tissue to earlier onset of diseases, reducing fertility and mammary gland and prostate cancer [19].

Furthermore, the issues of binding affinities to the ERs and the dose of BPA seem to be the heart of the controversy. BPA was able to compete with oestradiol in binding to ERs [40]; also its toxic effects have been proposed to be mediated through binding to ER $\alpha$ or ER $\beta$. [34]. Perinatal exposure of female rats to low or high doses of BPA modified the gene expression signature of their mammary glands tissue [22].
Ki-67 is a nuclear protein being associated with cellular proliferation and was originally identified in the early 1980s [8]. The most prevalent analysis method of Ki-67 antigen is the immunohistochemical evaluation. It was shown that $\mathrm{Ki}-67$ nuclear antigen is expressed in certain phases of the cell cycle, namely $\mathrm{S}, \mathrm{G1}, \mathrm{G} 2$, and $\mathrm{M}$ phases, but is non existing in $\mathrm{G0}$ [29]. In samples from normal breast tissue, it was found that Ki-67 is also expressed at low levels (3\% of cells) in ER-negative cells, but not in ER-positive cells. By means of immunostaining with the monoclonal antibody $\mathrm{Ki}-67$, it is possible to assess the growth fraction of neoplastic cell populations [36].

Due to the limitations of the inherent studies in human, it is still needed of more experimental animal work to help of understanding its potential effects on human especially during certain critical windows of development. We conduct this work with the aim to understand whether in utero exposure to environmentally relevant levels of BPA may affect the proliferative activity of the rat vagina of their offspring in their adult age. Due to the literature controversy about inducing proliferative and potentially carcinogenic role, the current study tested the vagina by using the proliferative marker, Ki-67. To provide new insights into the potential role of ERs in the activity of BPA, the study investigated their distribution. Lastly, the ultrastructural changes of the vagina and whether they impose carcinogenic stress on it were investigated.

\section{MATERIALS AND METHODS}

The present study was carried out on 60 adults (20 male and 40 female) Sprague-Dawley albino rats, weighing 180-250 g. Male and female rats were inbred and maintained under a controlled environment (22 $\pm 2{ }^{\circ} \mathrm{C} ; 12 \mathrm{~h}$ light cycle) and given food and water ad libitum. The concentration of phytoestrogens in the diet was not evaluated because food intake was equivalent for control and experimental rats and both groups were exposed to the same levels of phytoestrogens [38]. Two females and one male were housed in a cage. During routine breeding checks, each one with noticeably sperm-positive vaginal smears was removed and placed in a separate cage.

\section{Experimental design}

Gravid rats were divided into three groups (10 per group). G1 control group received an equal amount of sesame oil to those of treated groups. G2 group was 
administered by gavage $0.1 \mathrm{mg} \mathrm{BPA} / \mathrm{kg}$ body weight (low-dose group) dissolved in sesame oil; G3 group received $50 \mathrm{mg} \mathrm{BPA} / \mathrm{kg}$ body weight (high-dose group) dissolved in sesame oil [30]. BPA was purchased from Sigma-Aldrich Co. St. Louis, MO, USA. The treatment was performed daily from day 10 to day 20 postconception. The litters of each group were transferred to surrogate dams immediately after birth. The female offsprings of each group were weaned at day 21 and maintained until 3 months old. These female rats were followed before sacrifice to determine if they were undergoing a normal oestrus cycle by vaginal smear (by swab or cotton bud moistened with saline) using Shorr's stain solution. To define the phase of oestrus cycle, every morning from 9-11 am vaginal smears were taken and processed [9]. During the dioestrus phase the rats were euthanised by intraperitoneal injection of $75 \mathrm{mg} / \mathrm{kg}$ pentobarbital. The vagina was dissected for histological, immunohistochemical and ultrastructural analysis.

\section{Light microscopic examination}

Small pieces of the vagina were fixed in $10 \%$ formol saline solution at $4^{\circ} \mathrm{C}$ for $24 \mathrm{~h}$, processed, embedded in paraffin to prepare $5 \mu \mathrm{m}$ sections and stained with haematoxylin and eosin to compare the thickness of the epithelial cells by counting the layers of epithelial mucosa of the three groups and to detect cells with pyknosis. Immunohistochemical staining for oestrogen receptors and proliferation marker (Ki-67) was performed.

\section{Immunohistochemical examination}

Immunostaining required antigen retrieval by boiling tissue sections in citrate buffer $\mathrm{pH} 6.0$ in microwave for 2 min followed by cooling at room temperature. Then they were incubated with the ready to use primary antibody for $1 \mathrm{~h}$. The following primary antibodies were applied: Rabbit Monoclonal Antibody, anti-Oestrogen Receptor, Clone: SP1, which recognises $\mathrm{ER} \alpha$, (the positive control is breast ductal carcinoma) and rabbit Monoclonal Antibody, anti-Ki-67, Clone: SP6, (the positive control is the tonsil). Then, ultravision universal detection system was used to detect the immune reaction. This was formed of biotinylated anti-polyvalent secondary antibody, streptavidin peroxidase and diaminobenzidine (DAB). The sections were then counterstained using Mayer's haematoxylin. For negative control sections, the same procedure was followed with the omission of incubation into the primary antibodies. All these materials were purchased from Thermo Scientific, Lab Vision-Fisher Scientific, USA.

\section{Morphometric study}

Immunohistochemical sections were submitted for image analysis. High-resolution whole-slide digital scans of all glass slides were created with a ScanScope scanner (Aperio Technologies, Inc.). The digital slide images were viewed and analysed using Aperio's viewing and image analysis tools. For the area per cent of $\mathrm{ER} \alpha, 5$ square fields of a fixed area of $0.2645 \mathrm{~mm}^{2}$ were randomly selected in each slide. The colour separation algorithm (Aperio Technologies, Inc.) was then applied to measure the area per cent of ER $\alpha$ immunopositivity (the brown colour of DAB). The algorithm was then run on the selected area and it generated an intensity range colour markup image, segmenting and colour coding different parts of the image according to the intensity of positive staining. The intensity ranges showed 4 colours: red indicated strong staining, orange indicated moderate staining, yellow indicated weak staining, and blue indicated negative staining. The area for each of these 4 intensity categories (expressed as a per cent relative to the total analysis area), together with the average optical density, were also given as numerical output. Because of some background staining, we considered the weak staining as being negative.

For Ki-67, in each section, 5 fields were randomly selected. The nuclear analysis algorithm (Aperio Technologies, Inc.) was then applied to quantify nuclear staining and intensity. The algorithm generates a markup image highlighting the detected nuclei which are colour-coded according to their classification. Nuclear staining is classified as follows, based on staining intensity: Blue $=0$, Yellow $=1+$, Orange $=2+$, Red $=3+$. Output results included: percentage positive nuclei [0.0-100.0\%]. The proliferative Ki-67 index was determined as the percentage of positive cells within the cells of the field.

Number of strata per field: 10 sections per group were subjected to morphometry for the number of strata in the vagina. Five measurements were taken per field and their mean was calculated and recorded as the reading of the field.

The data obtained were statistically analysed by comparing the mean values of different groups by analysis of variance ANOVA test using SPSS 9 software. $\mathrm{P}$ value $<0.05$ was considered statistically 


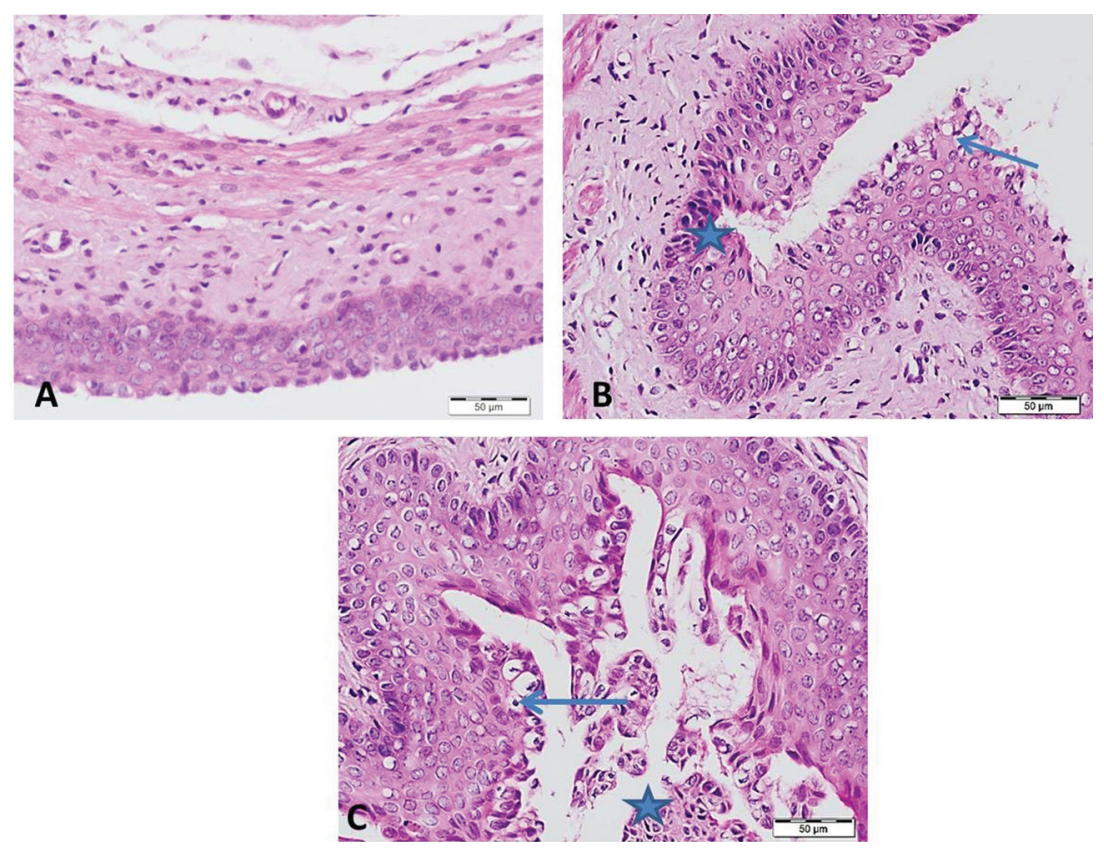

Figure 1. Light photomicrographs of vagina of rat stained with haematoxylin and eosin (scale bar $=50 \mu \mathrm{m}$ ), showing: A. Group 1, normal thickness of vaginal mucosa which is formed of non-keratinised stratified squamous epithelium with underlying vascular connective tissue lamina propria; B. Vaginal mucosa of rat received small dose of bisphenol Group 2, showing focal patches of decreasing of epithelial lining layers (star) that have pyknotic nuclei and degenerated cytoplasm, between areas with abnormal increased numbers of layers of cells and many epithelial cell with hydropic degeneration and pyknotic nuclei (arrow); C. Group 3, vaginal mucosa of rat that received high dose of bisphenol showing large areas of epithelial desquamation (star) and many cells completely degenerated (arrow), in addition to patches of markedly increased layers of cells.

significant. For correlation study, Pearson test was performed. P value for the ' $r$ ' $<0.05$ was considered statistically significant [25].

\section{Ultrastructural study}

Fine fragments of the vagina were fixed in $2.5 \%$ glutaraldehyde and postfixed in osmium tetraoxide $1.0 \%$, dehydrated in ascending grades of alcohol, cleared in propylene oxide and embedded in epon. Semithin sections were prepared and stained with toluidine blue. Ultrathin sections were prepared and stained with uranyl acetate and lead citrate and examined by Jeol Japan (Jem-1400) transmission electron microscope [11].

\section{RESULTS}

Light microscopic examination of vagina revealed degeneration of the epithelial lining with focal patches of decrease of epithelial layers especially in rats received small dose of bisphenol (Fig. 1B). High dose of BPA increased the cytoplasmic hydropic degeneration which appeared as vacuolation of cytoplasm with foamy appearance. BPA induced proliferative changes in adjacent or remote areas to these degenerative patches with increased number of strata. Although the number of layers was accentuated, many cells in different strata, even the basal ones showed areas of hydropic degeneration and vacuolations and pyknotic changes. Also, the nuclei of most of layers of epithelial cells became pyknotic. The epithelium appeared riddled with cavities containing pyknotic nuclei (Fig. 1C).

Immunohistochemistry of ER $\alpha$ demonstrated normal positive distribution of $E R \alpha$ of normal control vagina mucosa (Fig. 2A), while both low and high doses of BPA produced down-regulation of the ER $\alpha$ that appeared markedly in the high dose group (Figs. 2B, C).

Immunostaining of the vaginal epithelium using Ki-67 primary antibody as an indicator for cellular proliferation, demonstrated very few cells with positive nuclei, that restricted to the superficial cells of normal control sections (Fig. 3A), while vaginal epithelium of rats received small dose of BPA showed increase number of positive nuclei mainly in the basal columnar cells (Fig. 3B). Vagina of rats received higher doses showed marked increase of positive cells of both basal columnar cells and the middle polyhedral cells (Fig. 3C). 


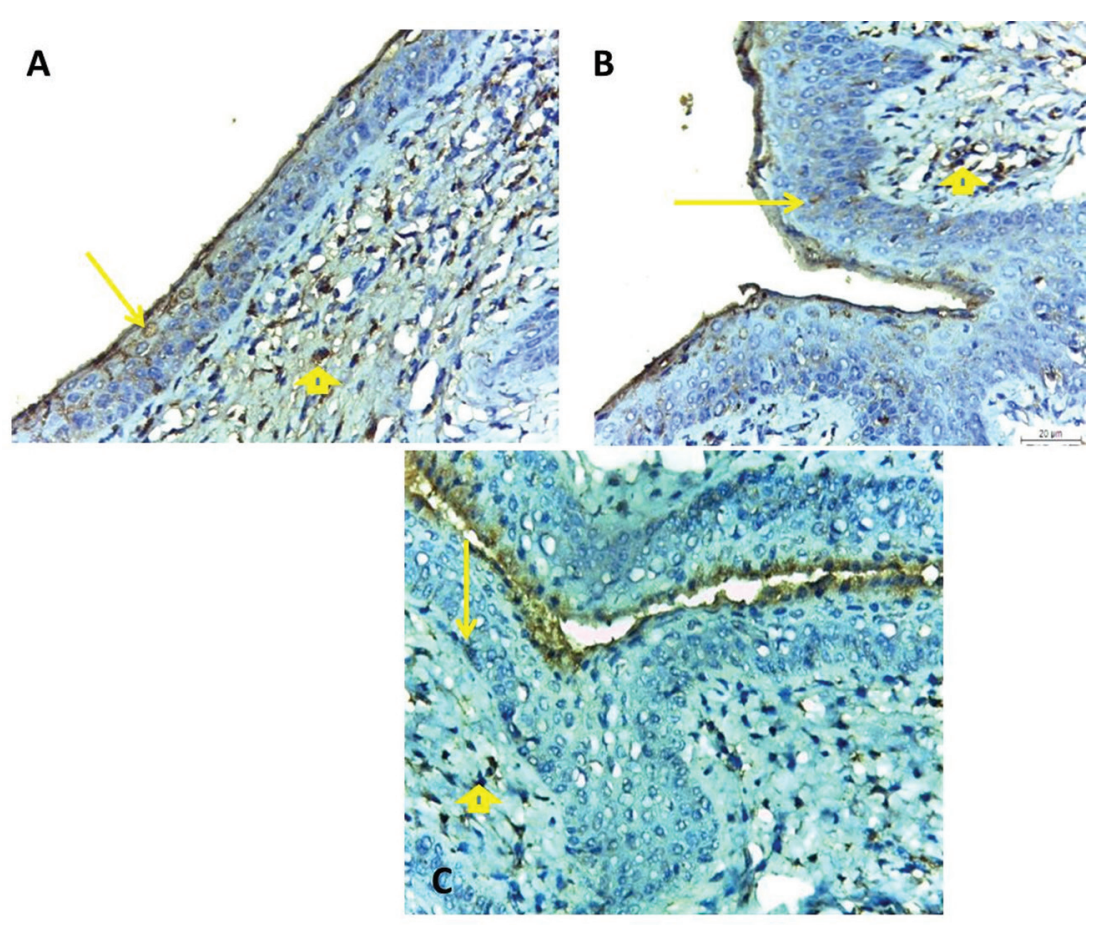

Figure 2. Light photomicrographs of sections of vagina immuno-stained with oestrogen receptors $\alpha$ (ER $\alpha$ ) (scale-bar $=20 \mu \mathrm{m}) ; \mathbf{A}$. Group 1, control vagina showing many immuno-positive cells in the epithelium (arrow) and stroma (arrow head); B. Group 2, vagina of rat received small dose of bisphenol showing moderate decreased expression of ER $\alpha$ in the epithelium (arrow) and stroma (arrow head); C. Group 3, vagina of rat received high dose of bisphenol showing a marked decrease of $\mathrm{ER} \alpha$ immune expression in both epithelium (arrow) and stroma (arrow head).

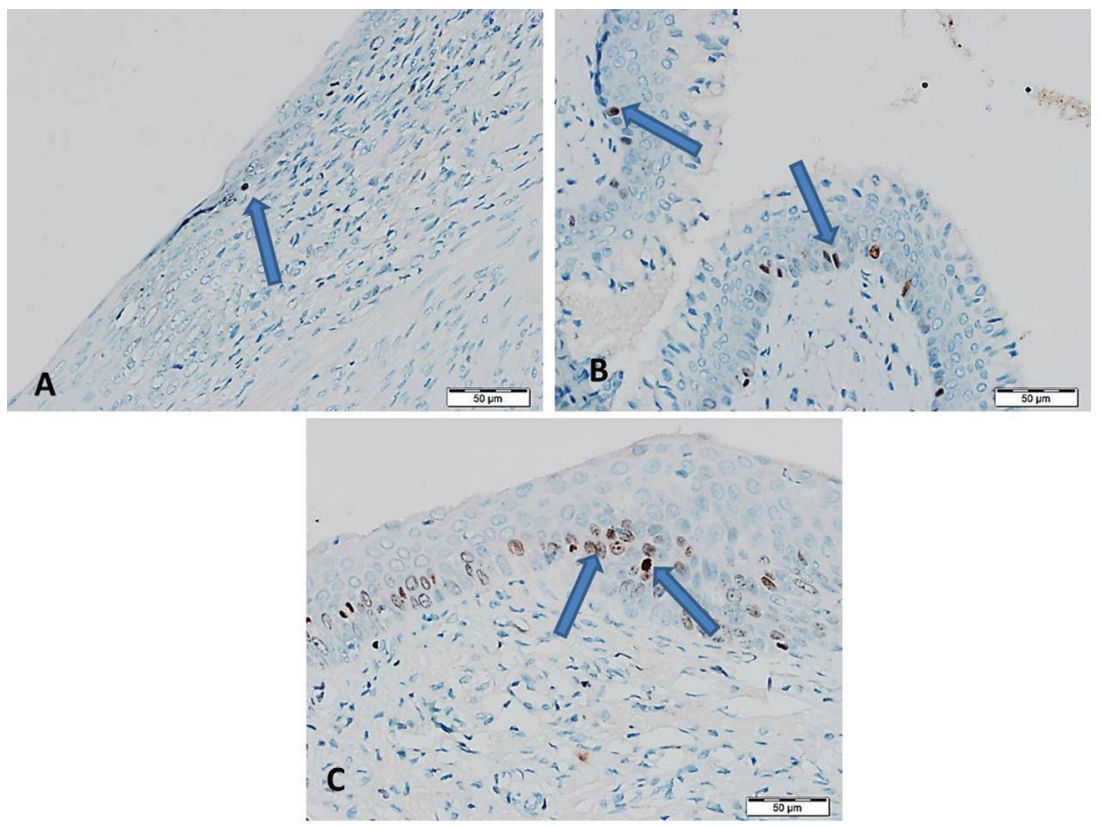

Figure 3. Light photomicrographs of sections of vagina immuno-stained with proliferation marker Ki-67 as a proliferative factor indicator (scale bar $=50 \mu \mathrm{m}$ ), showing: A. Group 1, normal control rat with very few positive epithelial cells (arrow); B. Group 2, vaginal mucosa of rat received small dose of bisphenol showing moderate increase of positive epithelial cells mainly in the stratum basalis (arrows); C. Group 3 , vaginal mucosa of rat received high dose of bisphenol showing marked increase of number of positive epithelial cells in both stratum basalis and nearby polygonal cells (arrows). 
Table 1. Area per cent of oestrogen receptors $\alpha$ (ER $\alpha$ ) immunopositive cells per field

\begin{tabular}{lcc}
\hline & Mean \pm SD & P \\
\hline Group 1 & $26.07 \pm 5.71$ & - \\
Group 2 & $17.47 \pm 3.82$ & $0.028^{*}$ \\
Group 3 & $7.28 \pm 3.94$ & $0.001^{*}$ \\
\hline
\end{tabular}

*p value $<0.05$ significant compared to Group 1

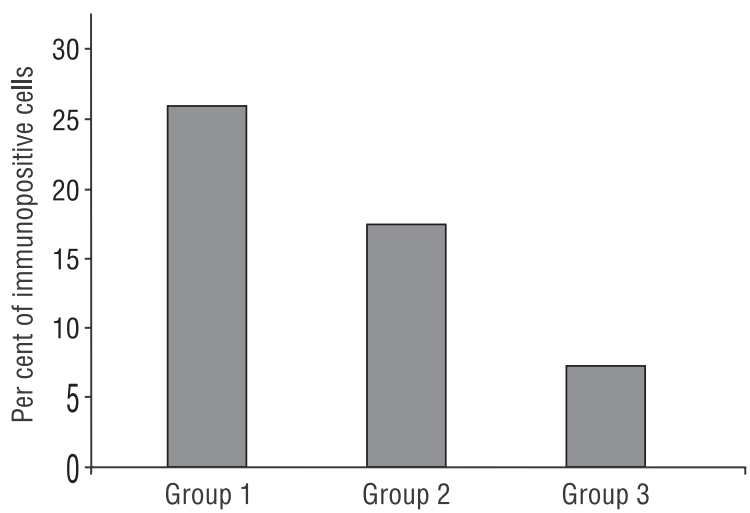

Figure 4. Area per cent of oestrogen receptors $\alpha$ (ER $\alpha)$ immunopositive cells per field.

Area per cent of ER $\alpha$ downfallen significantly in both BPA treated groups and was dose dependent compared to control (Table 1, Fig. 4). A significant increase of proliferating epithelial cells was detected in BPA low dose treated group compared to the control one and accentuated in the high dose treated group (Table 2, Fig. 5). The number of strata increased significantly only in high dose group compared to the control (Table 3). A significant negative correlation between the number of strata in the vagina and the area per cent of ER $\alpha$ per field was seen $(r=-0.734$, $p=0.001$ ) (Fig. 6). However, a significant positive correlation between the number of strata in the vagina and Ki-67 percentage of immunopositive cells was detected ( $r=0.805, p=0.001$ ) (Fig. 7).

Electron microscopic study of vaginal epithelium of rats that received low dose BPA showed clear separation between basal columnar cells that became separated from each other by irregular empty areas, also the basal cells started to suffer from cytoplasmic degeneration and vacuolations with mitochondrial degeneration and rarefaction of their cristae (Figs. 8A, B). High dose of bisphenol led to marked increase of cytoplasmic degenerations and cytoplasmic intermediate keratin filaments were detached from the inner-side of
Table 2. Percentage of proliferation marker Ki-67 immunopositive cells per field

\begin{tabular}{lcc}
\hline & Mean \pm SD & P \\
\hline Group 1 & $0.55 \pm 0.08$ & - \\
Group 2 & $7.68 \pm 1.16$ & $0.001^{*}$ \\
Group 3 & $11.98 \pm 2.08$ & $0.001^{*}$ \\
\hline
\end{tabular}

${ }^{*} p$ value $<0.05$ significant compared to Group 1

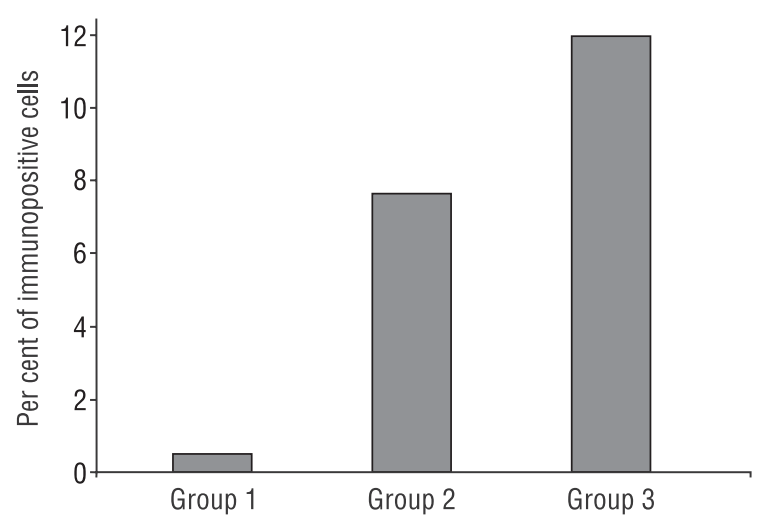

Figure 5. Percentage of proliferation marker Ki-67 immunopositive cells per field.

Table 3. Number of strata of the vaginal epithelium

\begin{tabular}{lcc}
\hline & Mean \pm SD & P \\
\hline Group 1 & $9.2 \pm 1.92$ & - \\
Group 2 & $11.4 \pm 2.30$ & 0.286 \\
Group 3 & $14.6 \pm 2.11$ & $0.005^{*}$ \\
\hline
\end{tabular}

${ }^{*} p$ value $<0.05$ significant compared to Group 1

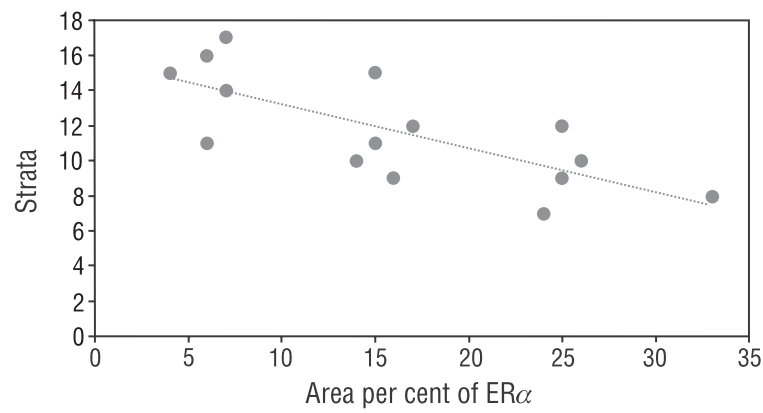

Figure 6. Correlation between the numbers of strata of the vagina and area per cent oestrogen receptors $\alpha(\mathrm{ER} \alpha)$.

the plasmalemma and became clumped as dark irregular dots in the cytoplasm. Nuclei of middle polyhedral cells showed irregularity in their nuclear membrane by the effect of large cytoplasmic vacuoles (Figs. 8C, D). 


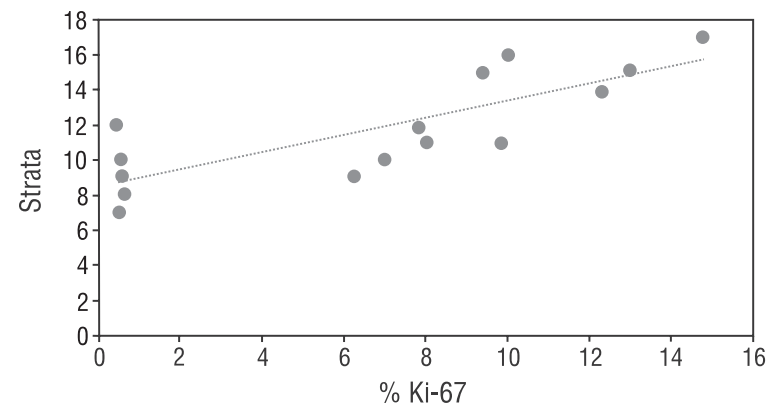

Figure 7. Correlation between the number of strata of the vagina and proliferation marker Ki-67 percentage of immunopositive cells.

\section{DISCUSSION}

Exposure to ED chemicals during critical periods of development as prenatal or early postnatal period could result in adverse effects to wildlife and humans. They may influence growth, reproduction, and development [17]. A lot of studies analysed the potential role of BPA on many organs and tissues. They gave marking, but not conclusive evidence, on its role in inducing proliferative and precancerous changes up to even frank carcinoma, like ductal carcinoma of the mammary glands [23], testes and prostate carcinoma [16].

The current work showed that exposure to BPA both in low environmental and high doses exerted degeneration of the vaginal epithelium with desquamation, hydropic degeneration and pyknosis. With high dose of BPA, there was extensive desquamation in addition to nearby areas of reactive thickening. The female reproductive tract is the major target of oestrogens. Their action is primarily mediated via binding to specific intracellular receptors in target cells [39]. Contrary to the current work, mice exposed prenatally to BPA did not show vaginal or uterine changes [33]. Laws et al. [15] found that monitoring changes in the vaginal epithelium of adult rats was
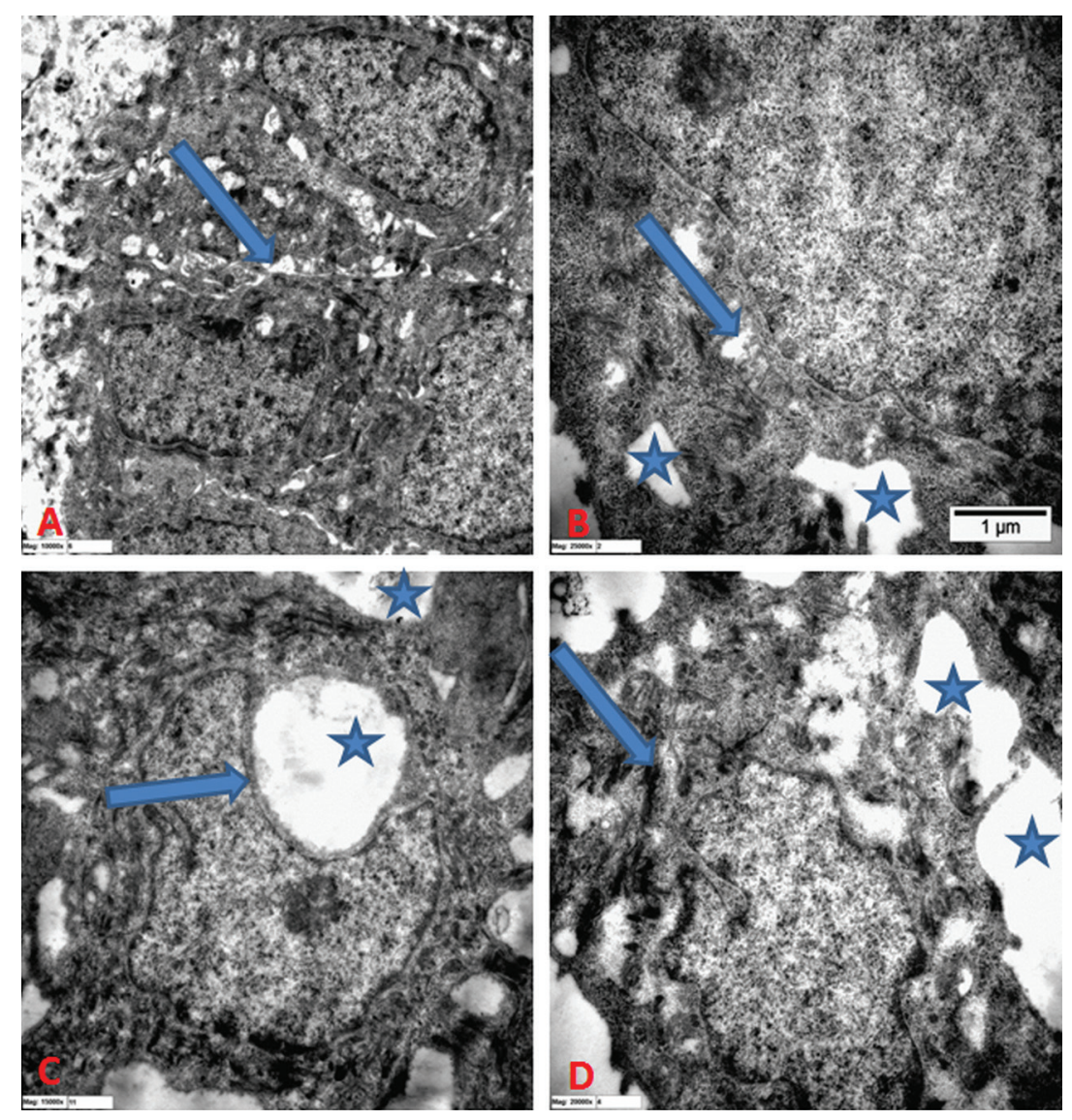

Figure 8. Electron micrographs of epithelial lining of vagina of rat received small dose of bisphenol Group 2, (A and B) showing increase of intercellular space between basal cells (arrow in A). Also, the cytoplasm of many of basal cells has small irregular vacuolations (stars in B) and degeneration of the cristae of the mitochondria (arrow in B). High dose of bisphenol Group 3 (C and D) exaggerated the cytoplasmic degeneration and vacuolation in most cells of epithelial layers (stars) that introduce severe indentation of the nucleus (arrow in C). Also there is marked clumping of the intermediate keratin filaments (arrow in D). 
the least effective method for detecting oestrogenic activity for BPA. The discrepancy of the results may be referred to different models of animal studied.

Oestrogens stimulate vaginal epithelium proliferation in vivo and play a critical role in vaginal growth, epithelial morphogenesis, cyto-differentiation, and secretory activity. The role of ER is studied as a probable key of how it induces proliferative changes in the vagina that promote to carcinomatous changes. ER $\alpha$ localises both nuclear and intracytoplasmic [26]. The present findings showed that the immune expression of ER $\alpha$ was markedly reduced after prenatal exposure to BPA and this was confirmed by the morphometric measurement of the area per cent of expression of the antibody. There is an inverse relationship of decreased immune expression of $E R \alpha$ with increased dose of BPA. This degradation of the sites of ER $\alpha$ is claimed, in this work, to be the mechanism of producing the histological degeneration in the vaginal epithelium. There is a decrease of cell receptors in the stroma similar to that of the epithelium. Previous work claimed that even at very low levels, xeno-oestrogens, being oestrogenic EDs can cause toxicological effects by binding hormone receptors, mimicking hormones or blocking their activities [6]. ER $\alpha$ was abundant in the vagina in stromal cells and mainly expressed in the basal and para-basal epithelial layers [18]. ER $\beta$ alone was not sufficient to mediate oestradiol induced epithelial proliferation in absence of ER $\alpha$ [3]. From the abundance of $E R \alpha$ and fewer distribution of $\operatorname{ER} \beta$ in the female genital tract [39], it is plausible to be the key igniting the action of BPA. The immune expression of ER $\alpha$ in the current work confirms that idea. BPA may directly affect the expression of ER-controlled genes involved in the morphogenesis of these organs. In addition, BPA-induced alterations that specifically affect hypothalamic-pituitary-gonadal axis function may further contribute to the anomalies observed in adulthood, long after the cessation of BPA exposure [20].

In utero exposure of rats to low doses of BPA, similar to amounts typically found in the environment, elicits long-term changes in ER $\alpha$ expression [13]. BPA significantly downregulates their expression, leading to striking morphologic changes in the differentiation and cornification of vagina [30]. Down-regulation of $\mathrm{ER} \alpha$ expression in the uterus after neonatal exposure to diethylstilboesterol as potent synthetic oestrogen was reported [21]. The mechanisms underlying the downregulation of $\mathrm{ER} \alpha$ expression may antagonise the action of endogenous oestrogens, because there are differences in the existence of tissue-specific ER coactivators [1]. BPA being an ED chemical with weak oestrogenic activity potentiates playing similar role as potent oestrogenic substances.

Vaginal epithelial proliferation was mediated indirectly through stromal $\mathrm{ER} \alpha$, and both epithelial and stromal ER $\alpha$ were required for oestrogen-induced cornification and stratification [2]. Also, Cooke et al. [5] proposed that whereas the nature of the oestradiol induced stromal signalling that induces epithelial proliferation is unknown; it is likely to involve growth factors. Its effects on stromal cells could also involve changes in the stromal extracellular matrix, basement membrane, or both, with secondary effects on epithelial cell secretory activity. ER $\alpha$ down-regulation seems to be responsible for the observed altered vaginal morphology. Similarly, Schmidt et al. [28] demonstrated that BPA is characterised by a functional anti-oestrogen property, very likely the result of a lack of ability to activate ER-mediated transactivation after binding to the receptor.

The present work shows controversy results to those of Markey et al. [20]; their findings included decreased weight of the vagina and increased expression of $\mathrm{ER} \alpha$ and progesterone receptors in the luminal epithelium of the endometrium and subepithelial stroma. These observations were reported in the uterus and not on the vaginal epithelium or its stroma as in the current results. It may be explained by variation in the expression of $\mathrm{ER} \alpha$ in different parts of the female genital tract.

BPA administered perinatally produces measurable and long lasting effects at doses that are $10^{6}$-fold lower than that required to induce the uterotrophic effect in prepubertal mice. This indicates the critical sensitivity of the developing organism to environmental oestrogen exposure [19]. BPA slightly induced MCF-7 cell proliferation at a higher level than oestradiol. It showed competitive inhibition to ER at levels higher 50,000 folds than oestradiol and it is recommended that its migration from epoxy resins or polycarbonate products should be controlled not to exceed a safety levels for humans, even if it is a weak oestrogenic chemical [14].

Since Ki-67 is expressed in all proliferating cells, including normal and tumour cells, it is used as an excellent marker of the cell proliferation [24, 32]. To trace these proliferative changes, immune expres- 
sion of Ki-67 was conducted. It showed increased proliferative cells to compensate for accelerated degeneration that was induced by BPA. It occurred under environmentally allowed dose as well as in high dosage. It is restricted to the basal columnar cells of stratum basalis, indicating marked vulnerability of these naturally rapidly dividing cells. It could be due to mutations of the genes encoding transcription and translation processes during mitosis. The carcinogenic potential of BPA has been studied in vitro. High doses of BPA have induced cell-transforming activities and aneuploidy in Syrian hamster embryo cells, suggesting that it has the potential to be genotoxic [35]. Antigen Ki-67 is a nuclear protein that is associated with cellular proliferation [7]. This means that these areas were subjected to kinds of unusual stresses which induced proliferative changes hampered by degenerative ones. This may lead to metaplastic/anaplastic changes. This evidence runs with the increased incidence of vaginal adenocarcinoma in adult daughters of mothers exposed to strong oestrogeinc drugs like diethylstilboesterol during pregnancy. In agreement with these findings and reflecting the proliferative machinery in this situation, there was an increased incorporation of bromodeoxyuridine into the DNA of endometrial gland epithelial cells exposed to BPA [20]. This raises significantly the issue of induction of precancerous or cancerous lesions.

The ultrastructural changes prove the dose relation changes on the epithelium with indentation of the nuclei and clumping of the cytoplasmic intermediate filaments with missing their contact points with the cell membrane and seized to the perinuclear zone. This distorts the cytoskeletal architectural support of the cell and fastens devitalisation of the cell. The distorted arrangement of the intermediate filament explains the detached epithelial cells seen ultrastructurally and the patchy decreased number of epithelial strata histologically detected.

The present findings showed extensive mitochondrial damage in the epithelial cells. Swollen mitochondria and degenerated cristae, as an evidence of mitochondrial degeneration, have been shown to cause structural damage in plasma membrane integrity and deficiency in adenosintriphosphat synthesis leading to cell necrosis [27]. The cytoplasm was markedly riddled with extensive vacuolation and few intracellular organelles. The striking finding of loss of cell to cell adherence and no junctional connection of the epithelium seen is explained by loss of oestrogenic effect. It seems that BPA, through its weak oestrogenic action decreased the number of receptors in the tissue. This impedes the energy machinery of the cell in addition to the intra or trancellularly skeletal adhesion proteins like intermediate filament proteins. Competitive inhibition of its remaining receptors is another possible mechanism of its action. There was no reported ultrastructure literature on the effects of BPA on the female genital tracts or gonads showing whether it has deleterious effects or not. This is the first time to report these ultrastructural changes and to show the way of BPA acting on the vaginal epithelium intracellularly and the vulnerable organelles hit by it.

\section{CONCLUSIONS}

These findings may help to elucidate the potential impact of EDs in vivo and predict the health risk of their environmental exposure on humans. The ubiquitous BPA shown obvious mix of degenerative and proliferative histological changes and clear damage of the cellular organelles. This stressful condition may predispose to neoplastic changes of the vagina.

\section{REFERENCES}

1. Abargues MR, Ferrer J, Bouzas A, Seco A (2013) Removal and fate of endocrine disruptors chemicals under lab-scale postreatment stage. Removal assessment using light, oxygen and microalgae. Bioresour Technol, 149C: 142-148.

2. Buchanan DI, Kurita T, Taylor J, Lubahn D, Cunha G, Cooke V (1998) Role of stromal and epithelial estrogen receptors in vaginal epithelial proliferation, stratification and cornification. Endocrinol, 139: 4345-4352.

3. Buchanan DL, Setiawan T, Lubahn DB, Taylor JA, Kurita T, Cunha GR, Cooke PS (1999) Tissue compartment-specific estrogen receptor: a participation in the mouse uterine epithelial secretory response. Endocrinology, 140: 484-491.

4. Calafat AM, Ye Y, Wong LY, Reidy JA, Needham LL (2008) Exposure of the U.S. population to bisphenol $A$ and 4-tertiary-octylphenol. Environmental Health Perspectives, 116: 39-44.

5. Cooke SP, Buchanan DL, Young P, Setlawan T, Brody J, Korach KS, Taylor J, Lubahn DB, Cunha GR (1997) Stromal estrogen receptors mediate mitogenic effects of estradiol on uterine epithelium. Proc Natl Acad Sci USA, 94: 6535-6540.

6. Dang VH, Choi KC, Jeung EB (2009) Estrogen receptors are involved in xenoestrogen induction of growth hormone in the rat pituitary gland. J Reprod Dev, 55: 206-213.

7. Fung $A D$, Cohen $C$, Kavuri S, Lawson D, Gao X, Reid MD (2013) Phosphohistone h3 and Ki-67 labeling indices in cytologic specimens from well-differentiated neuroendocrine tumors of the gastrointestinal tract and pancreas: a comparative analysis using automated image cytometry. Acta Cytol, 57: 501-508. 
8. Gerdes J, Schwab U, Lemke H, Stein H (1983) Production of a mouse monoclonal antibody reactive with a human nuclear antigen associated with cell proliferation. Int J Cancer, 31: 13-20.

9. Goldman TM, Murr AS, Cooper RL (2007) The rodent estrus cycle characterization of vaginal cytology and its utility in toxicological studies. Birth Defects Res (Part B), 80: 84-97.

10. Gray GM, Cohery JT, Cunha G, Hughes C, McConnell EE, Rhomberg L, Sipes IG Mattison D (2004) Weight of the evidence evaluation of low dose reproductive and developmental effects of bisphenol A. Human Ecolog Risk Assess, 10: 875-921.

11. Hayat MA (2000) Principals and techniques of electron microscopy: biological application. $4^{\text {th }}$ Ed. Cambridge University Press, Edinburgh, UK.

12. Honma S, Suzuki A, Buchanan DL, Katsu $Y$, Watanabe $H$, Iguchi T (2002) Low dose effect of in utero exposure to bisphenol $A$ and diethylstilbestrol on female mouse reproduction. Reprod Toxicol, 16: 117-122.

13. Khurana S, Ranmal S, Ben-Jonathan N. Exposure of newborn male and female rats to environmental estrogens (2000) delayed and sustained hyperprolactinemia and alterations in estrogen receptor expression. Endocrinology, 141: 4512-4517.

14. Kim HS, Han SY, Yoo SD, Lee BM, Park KL (2001) Potential estrogenic effects of bisphenol-A estimated by in vitro and in vivo combination assays. J Toxicol Sci, 26: 111-118.

15. Laws SC, Carey SA, Ferrell JM, Bodman GJ, Cooper RL (2000) Estrogenic activity of octylphenol, nonylphenol, bisphenol A and methoxychlor in rats. Toxicol Sci, 54: 154-167.

16. Lazúrová Z, Lazúrová I (2013) The environmental estrogen bisphenol $A$ and its effects on the human organism. Vnitr Lek, 59: 466-471.

17. Loder N (2000) Royal society warns on hormone disrupters. Nature, 406: 4-15.

18. MacLean AB, Nicol LA, Hodgins MB (1990) Immunohistochemical localization of estrogen receptors in the vulva and vagina. J Reprod Med, 35: 1015-1016.

19. Maffini MV, Rubin BS, Sonnenschein C, Soto AM (2006) Endocrine disruptors and reproductive health: the case of bisphenol-A. Mol Cell Endocrinol, 254-255: 179-186.

20. Markey CM, Wadia PR, Rubin BS, Sonnenschein C, Soto AM (2005) Long-term effects of fetal exposure to low doses of xenoestrogen bisphenol-A in the female mouse genital tract. Biol Reprod, 72: 1344-1351.

21. Medlock KL, Branham WS, Sheehan DM (1992) Long-term effects of postnatal exposure to diethylstilbestrol on uterine estrogen receptor and growth. J Steroid Biochem Mol Biol, 42: 23-28.

22. Moral R, Wang R, Russo I, Lamartiniere CA, Periera J, Russo J (2008) Effect of prenatal exposure to endocrine disruptor bisphenol A on mammary gland morphology and gene expression signature. J Endocrinol, 169: 101-112.

23. Murray TJ, Maffini MV, Ucci AA, Sonnenschein C, Soto AM (2007) Induction of mammary gland ductal hyperplasias and carcinoma in situ following fetal bisphenol A exposure. Reprod Toxicol, 23: 383-390.

24. Nnene IO, Nieto JJ, Crow JC (2004) Cell cycle and apoptotic proteins in relation to ovarian epithelial morphology. Gynecol Oncol, 92: 247-251.

25. Petrie A, Sabin C (2005) Basic techniques for analysing data. In: Sugden M, Moore K eds. Medical Statistics at a Glance. $2^{\text {nd }}$ Ed. Blackwell Publishing Ltd., USA, pp. 55-57.

26. Raso MG, Behrens C, Herynk MH, Liu S, Prudkin L, Ozburn NC, Woods DM, Tang X, Mehran RJ, Moran C, Lee JJ,
Wistuba II (2009) Immunohistochemical expression of estrogen and progesterone receptors identifies a subset of NSCLCs and correlates with EGFR mutation. Clin Cancer Res, 15: 5359-5368.

27. Saggu SK, Chotaliya HP, Blumbergs PC, Casson RJ (2010) Wallerian-like axonal degeneration in the optic nerve after excitotoxic retinal insult: an ultrastructural study. BMC Neurosci, 11: 97-102.

28. Schmidt S, Degen GH, Seibel J, Hertrampf T, Vollmer G, Diel P (2006) Hormonal activity of combinations of genistein, bisphenol $A$ and 17 beta-estradiol in the female Wistar rat. Arch Toxicol, 80: 839-845.

29. Scholzen T, Gerdes J (2000) The Ki-67 protein: from the known and the unknown. J Cell Physiol, 182: 311-322.

30. Schönfelder G, Flick B, Mayr E, Talsness C, Paul M, Chahoud I (2002) In utero exposure to low doses of bisphenol A lead to long-term deleterious effects in the vagina. Neoplasia, 4: 98-102.

31. Schönfelder G, Friedrich K, Paul M, Chahoud I (2004) Developmental effects of prenatal exposure to bisphenol A on the uterus of rat offspring. Neoplasia, 6: 584-594.

32. Stygar D, Muravitskaya N, Eriksson B, Eriksson H, Sahlin L (2003) Effects of SERM (selective oestrogen receptor modulator) treatment on growth and proliferation in the rat uterus. Reprod Biol Endocrinol, 1: 40-48.

33. Suzuki A, Sugihara A, Uchida K, Sato T, Ohta Y, Katsu Y, Watanabe H, Iguchi T (2002) Developmental effects of perinatal exposure to bisphenol-A and diethylstilbestrol on reproductive organs in female mice. Reprod Toxicol, 16: 107-116.

34. Takayanagi S, Tokunaga T, Liu X, Okada H, Matsushima A, Shimohigashi Y (2006) Endocrine disruptor bisphenol A strongly binds to human estrogen-related receptor gamma (ERRgamma) with high constitutive activity. Toxicol Lett, 167: 95-105.

35. Tsutsui T, Tamura Y, Suzuki A, Hirose $Y$, Kobayashi M, Nishimura H (2000) Mammalian cell transformation and aneuploidy induced by five bisphenols. Int J Cancer, 86: 151-154.

36. Urruticoechea A, Smith IE, Dowsett M (2005) Proliferation marker Ki-67 in early breast cancer. J Clin Oncol, 23: $7212-7220$.

37. Vandenberg LN, Hauser R, Marcus M, Olea N, Welshons WV (2007) Human exposure to bisphenol A (BPA). Reprod Toxicol, 24: 139-177.

38. Varayoud J, Ramos JG, Bosquiazzo VL, Lower M, Muñozde-Toro M, Luque EH (2011) Neonatal exposure to bisphenol A alters rat uterine implantation-associated gene expression and reduces the number of implantation sites. Endocrinology, 152: 1101-1111.

39. Wang H, Eriksson H, Sahlin L (2000) Estrogen receptors alpha and beta in the female reproductive tract of the rat during the estrous cycle. Biol Reprod, 63: 1331-1340.

40. Washington W, Hubert L, Jones D, Gray WG (2001) Bispheno; a binds to low-affinity estrogen binding sites. In Vitro Mol Toxicol, 14: 43-51.

41. Welshons WV, Nagel SC, vom Saal FS (2006) Large effects from small exposure. III. Endocrine mechanisms mediating effects of bisphenol $A$ at levels of human exposure. Endocrinology, 147 (6 suppl.): 556-569.

42. Ye X, Pierik FH, Hauser R, Duty S, Angerer J, Park MM, Burdorf A, Hofman A, Jaddoe WW, Mackenbach JP, Steegers EA, Tiemeier H, Longnecker MP (2008) Urinary metabolite concentrations of organophosphorous pesticides, bisphenol A, and phthalates among pregnant women in Rotterdam, the Netherlands: the Generation R study. Environ Res, 108: 260-267. 